\title{
Extended analysis of the spot sign score's performance
}

\author{
Josser E. Delgado Almandoz, Albert J. Yoo, Michael J. Stone, Pamela W. Schaefer, Joshua N. Goldstein, Jonathan Rosand,
} Alexandra Oleinik, Michael H. Lev, R. Gilberto Gonzalez and Javier M. Romero

We have read with great interest Becker and Tirschwell's commentary (Stroke: 'Spotting' patients at the highest risk of hematoma growth. Nat. Rev. Neurol. 5, 526-528; 2009) $)^{1}$ on our work relating to the use of the CT angiography spot sign and the 'spot sign score' in the selection of patients with primary intracerebral hemorrhage for early hemostatic therapy. ${ }^{2}$ Here, we provide answers to the questions raised in their commentary regarding the sensitivity and specificity of each spot sign score group in our study for the prediction of hematoma expansion and, in addition, poor clinical outcome (Table 1).

Becker and Tirschwell's group was the first to recognize that the presence of contrast extravasation on CT angiography was a strong predictor of mortality in patients with primary intracerebral hemorrhage, ${ }^{3}$ which has been corroborated by other groups. ${ }^{4,5}$ Moreover, subsequent studies have also associated the presence of contrast extravasation on CT angiography with hematoma expansion and poor clinical outcome. .,4-10 $^{2}$

Interestingly, receiver operating characteristic analysis performed on the data from our study demonstrates that the maximum operating point is reached at a spot sign score $\geq 1$ for the prediction of both hematoma expansion and poor clinical outcome. This finding suggests that all patients with spot signs might merit treatment with early hemostatic therapy, regardless of the spot sign score. However, we believe that the role of the spot sign score in the selection of patients for early hemostatic therapy needs to be fully explored in future randomized clinical trials.

Division of Neuroradiology, Mallinckrodt Institute of Radiology, Washington University, Campus Box 8131, 510 South Kingshighway Boulevard, Saint Louis, MO 63110, USA (J. E. Delgado Almandoz). Division of Neuroradiology, Department of Radiology (A. J. Yoo, M. J. Stone, P. W. Schaefer, M. H. Lev, R. G. Gonzalez, J. M. Romero), Department of Emergency Medicine (J. N. Goldstein), Department of Neurology (J. Rosand, A. Oleinik), Massachusetts General Hospital, Harvard Medical School, 55 Fruit Street, Boston, MA 02114, USA.

Correspondence to: J. E. Delgado Almandoz delgadoj@mir.wustl.edu

doi:10.1038/nrneurol.2009.152-c1

\section{Acknowledgments}

This research was supported, in part, by a National Institute of Neurological Disorders and Stroke grant

Table 1 | The spot sign score in primary intracerebral hemorrhage

\begin{tabular}{lllll}
\hline \multirow{2}{*}{$\begin{array}{l}\text { Spot sign } \\
\text { score* }\end{array}$} & \multicolumn{2}{c}{ Hematoma expansion $(95 \% \mathrm{Cl})^{\ddagger}$} & \multicolumn{2}{c}{ Poor clinical outcome $(95 \% \mathrm{Cl})^{\S}$} \\
\cline { 2 - 5 } & Sensitivity & Specificity & Sensitivity & Specificity \\
\hline$\geq 0$ & $100(93.6-100)$ & $0(0-1.2)$ & $100(98.8-100)$ & $0(0-1.4)$ \\
$\geq 1$ & $87.5(75.9-94.8)$ & $92.9(89.5-95.5)$ & $33.7(28.4-39.2)$ & $89(84.6-95.2)$ \\
$\geq 2$ & $76.8(63.6-87)$ & $96.8(94.2-98.4)$ & $26.9(22-32.2)$ & $93.2(89.4-95.9)$ \\
$\geq 3$ & $60.7(46.8-73.5)$ & $99.7(98.2-100)$ & $15.2(11.4-19.7)$ & $97(94.1-98.7)$ \\
$\geq 4$ & $30.4(18.8-44.1)$ & $100(98.8-100)$ & $6.5(4-9.8)$ & $99.2(97.3-99.9)$ \\
\hline
\end{tabular}

*A score of zero indicated that no spot sign was identified on the CT angiogram. ${ }^{\ddagger}$ Hematoma expansion was defined as an increase $>30 \%$ or $>6 \mathrm{ml}$ of the initial intracerebral hemorrhage volume. sPoor clinical outcome was defined as a modified Rankin Scale score $\geq 4$ at 3 month follow-up.
(K23NS059774) to J. N. Goldstein, an American Heart Association Grant-in-Aid (0755984T) to

J. Rosand, and a NIH Specialized Programs of Translational Research in Acute Stroke grant to M. H. Lev.

Competing interests

M. H. Lev declares associations with the following companies: GE Healthcare, Millennium

Pharmaceuticals, Vernalis. See the article online for full details of the relationships. The other authors declare no competing interests.

1. Becker, K. \& Tirschwell, D. Stroke. 'Spotting' patients at the highest risk of hematoma growth. Nat. Rev. Neurol. 5, 526-528 (2009).

2. Delgado Almandoz, J. E. et al. Systematic characterization of the computed tomography angiography spot sign in primary intracerebral hemorrhage identifies patients at highest risk for hematoma expansion: the spot sign score. Stroke 40, 2994-3000 (2009).

3. Becker, K. J. et al. Extravasation of radiographic contrast is an independent predictor of death in primary intracerebral hemorrhage. Stroke $\mathbf{3 0}$, 2025-2032 (1999).

4. Kim, J. et al. Contrast extravasation on CT predicts mortality in primary intracerebral hemorrhage. AJNR Am. J. Neuroradiol. 29, 520-525 (2008).

5. Delgado Almandoz, J. E. et al. The spot sign score in primary intracerebral hemorrhage identifies patients at highest risk of in-hospital mortality and poor outcome among survivors. Stroke 41, 54-60 (2010).

6. Wada, R. et al. CT angiography “spot sign” predicts hematoma expansion in acute intracerebral hemorrhage. Stroke 38 , 1257-1262 (2007).

7. Goldstein, J. N. et al. Contrast extravasation on CT angiography predicts hematoma expansion in intracerebral hemorrhage. Neurology 68, 889-894 (2007).

8. Ederies, A. et al. Postcontrast CT extravasation is associated with hematoma expansion in CTA spot negative patients. Stroke 40, 1672-1676 (2009).

9. Thompson, A. L. et al. Defining the CT angiography 'spot sign' in primary intracerebral hemorrhage. Can. J. Neurol. Sci. 36, 456-461 (2009).

10. Hallevi, H., Abraham, A. T., Barreto, A. D., Grotta, J. C. \& Savitz, S. I. The spot sign in intracerebral hemorrhage: the importance of looking for contrast extravasation. Cerebrovasc. Dis. 29, 217-220 (2010). 